\title{
Structural effects of steel reinforcement corrosion on statically indeterminate reinforced concrete members
}

\author{
Ignasi Fernandez ${ }^{{ }^{1}}$, Manuel F. Herrador ${ }^{2}$, Antonio R. Marí ${ }^{1}$, Jesús Miguel Bairán ${ }^{1}$ \\ ${ }^{1}$ Department of Construction Engineering, Polytechnic University of Catalonia, Jordi
} Girona, 1-3, Barcelona 08034, Spain.

${ }^{2}$ Department of Construction Technology, Universidade da Coruña, Campus de Elviña, s/n, A Coruña 15172, Spain.

*corresponding author: ignasi.fernandez-perez@upc.edu

\section{Journal: Materials and structures}

\section{Highlights:}

- Experimental study on corrosion effects on statically indeterminate beams

- Internal forces redistribution due to steel corrosion

- Numerical modelling of structural effects due to deterioration

\begin{abstract}
Steel corrosion in reinforced concrete structures produces loss of reinforcement area and damage in the surrounding concrete. As a consequence, increases in deflections, crack widths and stresses may take place, as well as a reduction of the bearing capacity, which depends on the structural scheme and redundancy. In this paper an experimental study of twelve statically indeterminate beams subjected to different levels of forced reinforcement corrosion is presented. Different sustained loads were applied during the corrosion phase to assess their influence on the effects of corrosion. An important increase in deflections was registered in all corroded beams, especially in those subject to higher load levels. It was also found that the rate of
\end{abstract}


corrosion was affected by the load level. Internal forces redistributions due to induced damage were measured. Finally, the experimental results were compared with those predicted by a non-linear time-dependent segmental analysis model developed by the authors, obtaining in general good agreement. 


\section{Introduction and objectives}

Corrosion of steel is one of the most frequent and relevant deterioration processes suffered by reinforced concrete structures. Steel corrosion causes a reduction of the reinforcement area, changes in the reinforcing bars mechanical properties [1], cracks and spalling of the cover concrete, and a reduction of contact area between the reinforcement and the surrounding concrete. The most severe effect of reinforcement corrosion is the change in bond properties between steel and concrete [2, 3]. Also, volumetric expansion of corrosion products causes serious problems such as splitting stresses along corroded reinforcement, which might be harmful to the surrounding material. Generally, the splitting stresses are not tolerated by concrete, which leads to cracking and eventually spalling of the cover. As the reinforcement becomes more exposed, the corrosion rate may increase and accelerate the deterioration process $[4,5]$.

As a consequence of these phenomena, a reduction in the stiffness, bond properties, anchorage capacity, flexural and shear strengths takes place. Increasess of deflections, crack width and stresses in concrete and steel may be observed or measured in concrete structures as corrosion continues on, affecting their factor of safety against failure or their behavior under service conditions.

The ultimate capacity of reinforced concrete structures depends not only on their geometry, reinforcement (both amount and arrangement), materials properties and loading type, but also on their structural scheme. When a statically determinate structure undergoes steel corrosion, the reduction of steel area in the most corroded region may result in the formation of a plastic hinge and eventually evolve into a collapse mechanism. Therefore, it can be said that the reduction of flexural strength of the critical section leads to an almost proportional reduction of the capacity of the whole 
structure, as no external redundancy exists. However, large deflections and crack widths can be easily observed as corrosion advances, thus warning about the danger of structural collapse.

On the opposite side, statically indeterminate structures, due to their redundancy, have the capacity to redistribute internal forces between the more and less damaged regions, so that the formation of a plastic hinge does not necessarily lead to structural collapse [6]. As a consequence, they are more able to accommodate the effects of higher corrosion levels than statically determinate structures, so that more time between the first symptoms of corrosion and the eventual collapse may elapse. However, the capacity of internal forces redistribution and the higher stiffness associated with statically indeterminate structures (i.e continuous versus simply supported bridge decks) can hide the actual level of damage of the structure in such a way that it might not be adequately estimated by visual inspections.

Furthermore, corrosion of steel reinforcement takes place in structures which are in use and, therefore, permanently loaded. According to some researchers $[7,8]$, the rate of corrosion may be affected by the level of cracking previously produced by loads or constrained imposed deformations on the structure. However, very few tests have been carried out to verify such interaction.

In order to assess the serviceability performance and the safety of existing statically indeterminate reinforced concrete structures, analytical tools capable of adequately capturing the global structural effects of the reinforcement corrosion are needed. In particular, these tools should be validated against experimental results. Such models can be very useful not only for the assessment of existing structures but also for the design 
of new structures in order to satisfy the durability, functionality and safety requirements along their entire service life.

Even though many numerical models have been developed to predict the nonlinear and time dependent response of reinforced concrete structures, only very few of them take into account the structural effects of deterioration due to corrosion or the effects of strengthening interventions [9-13].

Many researchers have performed the study of corrosion effects for several years. Despite the size of the database of experimental studies, they mostly encompass simple specimens, reduced in dimensions and statically determinate. Thus, the structural effect on statically indeterminate beams is relevant to improve the existing database, to observe the effects of corrosion in these type of structures, and to verify analytical models.

In this paper an experimental study of the structural effects of steel reinforcement corrosion in statically indeterminate reinforced concrete beams is presented. Twelve continuous beams of two equal spans were subjected to three different levels of forced corrosion, defined using second Faraday's Law theory [14-16]. An additional set of three beams was left uncorroded to compare their results with those of the corroded beams. In addition, three different permanent loads - higher and lower than service loads - were applied prior to the corrosion phase to assess the influence of the load level on the corrosion rate and on its structural effects. The applied loads, reactions, deflections and strains in concrete and steel were measured during the corrosion process.

Finally, an extension of a pre-existing nonlinear analysis model [17] is also presented to consider in a simplified way the deterioration effects due to corrosion of steel. The 
reduction of steel area is implemented, as well as the loss of concrete cover due to expansiveness of corrosion products (spalling effect). In this manner, (1) redistribution of stresses between reinforcement and concrete and (2) redistribution of internal forces along the structure produced by deterioration are captured by the model through the decrease in steel area and section stiffness. A comparison between the results predicted by the model with those measured experimentally is presented, discussing the main differences among them and the suitability of this kind of models for assessing deteriorated reinforced concrete structures.

It should be noted that the goal of the present study is to experimentally verify the relation between the severity of corrosion (characterized quantitatively as steel loss percentage) and its effects on the structure. The use of impressed current as the means to artificially induce accelerated corrosion precludes analyzing the relation between the corrosion mechanism itself and its influence of the degree of corrosion, which would be the subject of studies of a different nature.

\section{Experimental program}

\subsection{Specimens description}

Twelve continuous two-span beams were cast. The beams had $5000 \mathrm{~mm}$ total length and two symmetric spans of $2400 \mathrm{~mm}$ between support axes. The cross-section was rectangular with $250 \mathrm{~mm}$ width and $120 \mathrm{~mm}$ depth. Concrete cover was $15 \mathrm{~mm}$ in the four faces.

Only longitudinal steel reinforcement was placed, trying to avoid the direct connection between the top and bottom steel faces in order to prevent interference in the corrosion process. Two $10 \mathrm{~mm}$ diameter bars were placed at the top of the beams, along their whole length, plus two extra bars of $10 \mathrm{~mm}$ diameter placed along the maximum 
negative bending moment zone. Two $12 \mathrm{~mm}$ diameter bars were placed at the bottom of the beams extended along the whole length. Fig. 1 describes the geometry of the crosssection and the reinforcement layout at critical points.
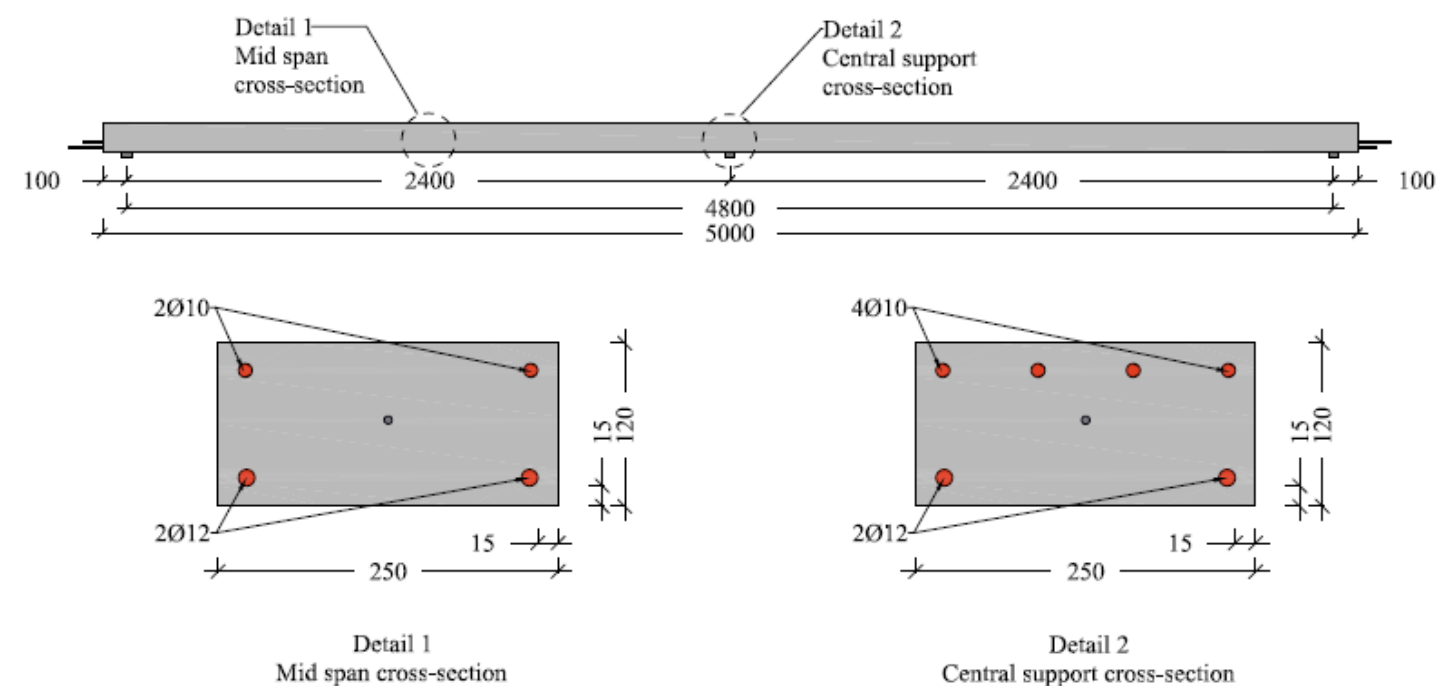

Figure 1.Geometrical specs of the specimen

\subsection{Test setup}

Four groups comprised of three specimens were arranged, each of them subject to a different corrosion level. Three corrosion levels were defined, plus a control group with no corrosion conditioning.

Within each group, every beam was submitted to a different permanent load to evaluate its effects during the corrosion process. One beam was left self-weighted, another beam saddled with a load $\mathrm{P}$, what was chosen slightly below to the service load obtained from the beam design, and the last one with a value of $2 \mathrm{P}$, which is higher than the service load level. Fig. 2 describes the test setup, where it can be seen how the load is applied over each beam. Table 1 describes the actual applied loads on each specimen. 


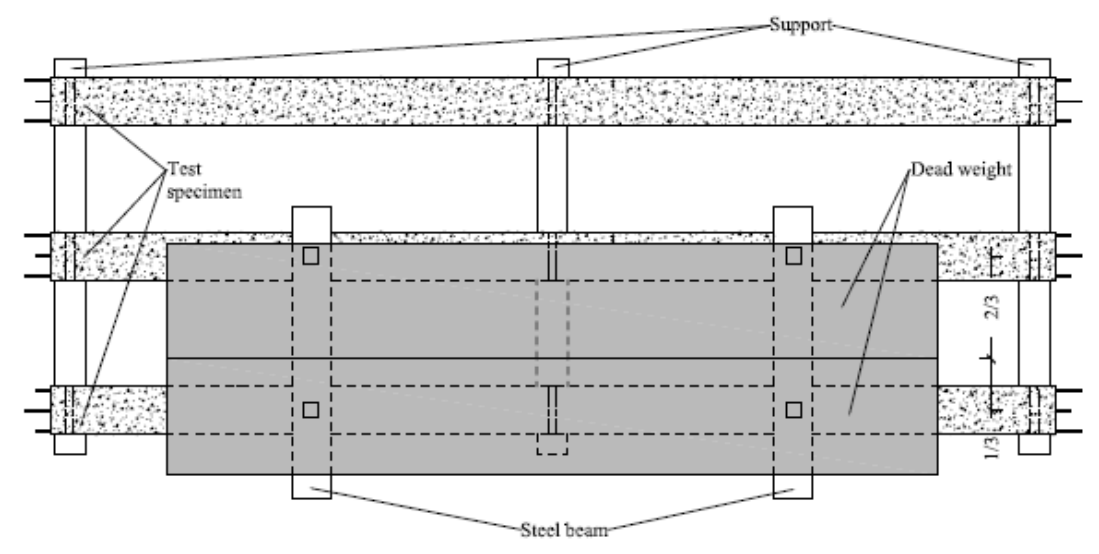

Figure 2. Test configuration during corrosion procedure

Table 1. Corrosion levels achieved, exposure days, applied load on span centre and material properties.

\begin{tabular}{|c|c|c|c|c|c|c|c|}
\hline & $\begin{array}{c}\text { Specime } \\
\mathbf{n}\end{array}$ & $\begin{array}{l}\text { Compressiv } \\
\text { e strength } \\
\text { (MPa) }\end{array}$ & $\begin{array}{c}\text { Tensile } \\
\text { strengt } \\
\text { h } \\
(\mathrm{MPa})\end{array}$ & $\begin{array}{l}\text { Modulu } \\
\text { s of } \\
\text { elasticit } \\
\text { y (MPa) }\end{array}$ & $\begin{array}{l}\text { Exposur } \\
\text { e time } \\
\text { (days) }\end{array}$ & $\begin{array}{c}\text { Steel loss (\% } \\
\text { Top/bottom } \\
\text { reinforcemen } \\
\text { t) }\end{array}$ & $\begin{array}{c}\text { Applie } \\
\text { d load } \\
\text { (kN) }\end{array}$ \\
\hline \multirow{3}{*}{ Group 1} & G1_2P & 43,03 & 3,38 & 37816 & & $6 / 14$ & 16,50 \\
\hline & G1_P & 41,40 & 3,67 & 37241 & 56 & $6 / 12$ & 6,74 \\
\hline & G1_SW & 40,93 & 3,00 & 35336 & & 9/11 & 0,00 \\
\hline \multirow{3}{*}{ Group 2} & $G 2 \_2 P$ & 39,36 & 2,70 & 36165 & & $6 / 15$ & 17.70 \\
\hline & G2_SW & 36,81 & 2,57 & 33929 & 42 & $6 / 10$ & 0,00 \\
\hline & $G 2 \_P$ & 41,10 & 2,69 & 36752 & & $7 / 15$ & 8,34 \\
\hline \multirow{3}{*}{ Group 3} & G3_SW & 37,64 & 2,70 & 37605 & & $15 / 15$ & 0,00 \\
\hline & G3_P & 38,55 & 2,62 & 35204 & 100 & $17 / 20$ & 8,47 \\
\hline & $G 3 \_2 P$ & 39,11 & 2,49 & 36984 & & $10 / 24$ & 17,50 \\
\hline \multirow{3}{*}{$\begin{array}{c}\text { Group } \\
\text { Uncorroded }\end{array}$} & $G R \_2 P$ & 38,61 & 2,64 & 36795 & & & 15,40 \\
\hline & $G R \_P$ & 38,28 & 2,67 & 36825 & 0 & $0 / 0$ & 7,98 \\
\hline & GR_SW & 38,20 & 3,17 & 37670 & & & 0,00 \\
\hline \multirow{2}{*}{$\begin{array}{c}\text { Steel } \\
\text { reinforceme } \\
\text { nt }\end{array}$} & $\begin{array}{c}10 \mathrm{~mm} \\
\text { diameter }\end{array}$ & -- & 550 & 200000 & & & \\
\hline & $\begin{array}{c}12 \mathrm{~mm} \\
\text { diameter }\end{array}$ & -- & 545 & 195000 & & & \\
\hline
\end{tabular}




\subsection{Material properties}

Concrete compressive strength and modulus of elasticity were determined at 28 days after casting, using a compression testing machine. Three cylindrical 150x300 mm specimens were tested for each type of concrete produced. Concrete splitting tensile strength was obtained by means of the Brazilian test, which involves indirect tensile measurement on cylindrical specimens equal to those used for compression tests. Table 1 describes the mechanical properties of the concrete specimens tested at 28 days of curing for all types of concretes produced as well as the modulus of elasticity.

The tensile behaviour of $400 \mathrm{~mm}$ long samples of reinforcement bars equal to those used in the beam's tests was determined using a tensile machine. Three displacement transducers were used to obtain longitudinal strains under the applied load up to failure, so that the modulus of elasticity in the elastic range and the full stress-strain curve were recorded.

Table 1 shows the properties (yield stress and modulus of elasticity) of the $10 \mathrm{~mm}$ and $12 \mathrm{~mm}$ diameter bars used for reinforcing steel used to cast the beams.

\subsection{Accelerated corrosion}

Accelerated corrosion methods open the possibility to reproduce corrosion episodes over structures in very short periods of time, as compared to natural corrosion. Obviously this form of corrosion mechanism has some drawbacks compared to natural corrosion testing. They are nevertheless necessary to investigate the effects on structures and materials over time within an appropriate investigation period. With this kind of methods it is possible to reproduce a 20-30 years' phenomenon in a few months with a reasonable agreement between the natural and induced corrosion effects. 
Following Faraday's law (Equation 1), it is possible to estimate the weight loss of steel due to corrosion, knowing the applied intensity over time, I(t), and the geometrical bar properties such as diameter and exposed length.

$$
E=\frac{m_{F e} \cdot \int \boldsymbol{I} \cdot d t}{V \cdot F}
$$

In Equation 1, $m_{F e}$ is the atomic mass, $\mathrm{V}$ is the steel valence that is taken as equal to 2 and $\mathrm{F}$ is Faraday's constant. As the applied intensity was an input during the test and it is also constant along time, it is possible to rewrite Faraday's law as Equation 2.

$$
\Delta \boldsymbol{m}=\frac{\boldsymbol{m}_{F e} \cdot \boldsymbol{I} \cdot \boldsymbol{t}}{V \cdot \boldsymbol{F}}
$$

Some researchers have observed $[14,18]$ that, using corrosion current densities below $350 \mu \mathrm{A} / \mathrm{cm}^{2}$ for accelerated corrosion, the difference between the corrosion rate estimated by means of Faraday's law and the corrosion rate registered from gravimetric methods (steel weight measure after accelerated corrosion) ranges between 5-10\%. Thus, by applying corrosion current density values below this threshold, it is possible to accurately estimate the achieved corrosion level with no need of destructive testing. Furthermore, current densities above this threshold imply moving the test further away from a natural corrosion process, inducing earlier cracking as well as (potential) differences between corrosion products. Also, bond between steel and concrete is affected by the corrosion rate [19]. In the presented work, corrosion rates below 350 $\mu \mathrm{A} / \mathrm{cm}^{2}$ were applied in order to corrode the specimens. The proposed goal was $10 \%$ steel weight loss in 28 days, which means a corrosion current density of $335 \mu \mathrm{A} / \mathrm{cm}^{2}$ and an equivalent current of 1.26 A for each beam. Taking these values into account, it was possible to estimate the different exposure times for each specimen according to the goal corrosion level and the current value. Each group of beams was supposed to be 
exposed to current during 42 days, 56 days and 100 days. Accordingly, the estimated corrosion level for each group was 10\% (for 56 days), 15\% (for 42 days) and $20 \%$ for (100 days).

Accelerated corrosion methods based on impressed current need depassivated steel for proper development. This means that it is necessary to previously depassivate steel bars. In the present study a $4 \%$ sodium chloride $(\mathrm{NaCl})$ solution in the water used for concrete casting was chosen in order to eliminate the passive layer by means of chloride attack.

Those beams to be corroded were placed over two pools located under the free span areas. In the middle of the cross-section a $6 \mathrm{~mm}$ diameter stainless steel wire was placed along the beam length to play the role of cathode in the corrosion circuit, the steel rebar being the anode. An irrigation system was set over the top face of the beams by means of a porous tube, which was used to keep the beams wet during all the exposure time. Concrete moisture had to be higher than usual in order to facilitate the corrosion process, reducing the resistivity of the concrete and interacting with the $\mathrm{NaCl}$ put in the mixture as an electrolyte for the corrosion cell. Additionally, to ensure a high level of moisture in the beam (thus reducing water and power consumption), every beam was wrapped individually in plastic sheets and burlap. The irrigation was programmed to take place for 5 minutes every 120 minutes. It was possible to connect different specimens in series, ensuring current would be the same on every specimen in the circuit, see Fig. 3 for details. 


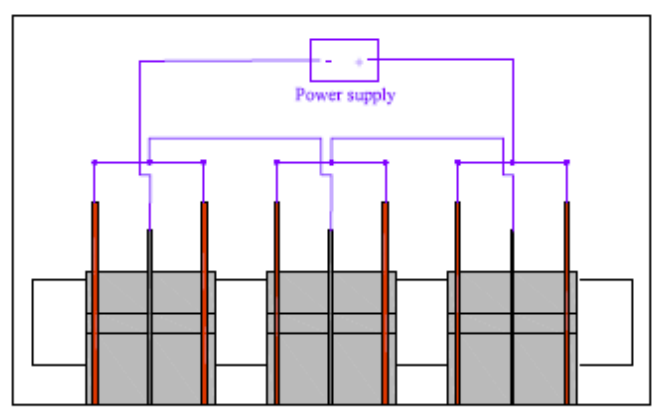

Figure 3. Connection setup

\subsection{Instrumentation}

Displacement transducers were placed to register beam deflections during the corrosion procedure at both mid-spans of each beam. Additional displacement transducers were placed at the free end of the steel bar to register bond-slip due to steel corrosion (one transducer per beam end).

Each beam had five load transfer points: three reactions and two load application points. In order to gather enough information to determine the bending moment law along the beam at any given time, four load cells were placed, obtaining the fifth unknown by equilibrium; the symmetry condition was avoided because of possible construction imperfections. Thus, reactions and applied load over each beam were known during the whole corrosion procedure.

Tensile and compressive steel stress in mid-span cross-section and tensile steel stress in middle-support cross-section were measured by means of resistive strain gauges glued on the steel bars. However, the extremely aggressive medium (due to the combined presence of $\mathrm{NaCl}$, water and applied current) made data acquisition difficult. Many gauges became useless in a few days; some did gather data for days, but none resisted the whole duration of the corrosion procedure. 


\section{Tests results}

\subsection{Initial adjustement and corrosion level reached}

The provided voltage suffered some variations during the first days until the environmental conditions stabilized. The current was applied by means of different power supplies programmed to regulate the voltage value to keep the design current constant. Thanks to the beam wrapping, it was possible to keep the beams at a high and roughly constant degree of humidity. During the test, the voltage was approximately between 20-30 V for each beam, which means that a power supply capable of providing at least $90 \mathrm{~V}$ for each group was needed.

In the beginning, the goal was to produce corrosion only in the bottom reinforcement steel. Eventually, some factors produced an extension of corrosion to the top reinforcement steel too. Corrosion of top reinforcement was observed for all the tested specimens, but at different exposure times.

Longitudinal cracks showed up in all of the specimens along the bottom steel reinforcement within the first five days of impressed current conditioning. This type of crack was also observed along the top reinforcement. Corrosion stains were very evident in the specimens and the corrosion products seeped through the longitudinal cracks. In addition, it was possible to observe longitudinal cracks in different zones along the beam with stains on the concrete that revealed corrosion of top bars also, see Fig. 4. 


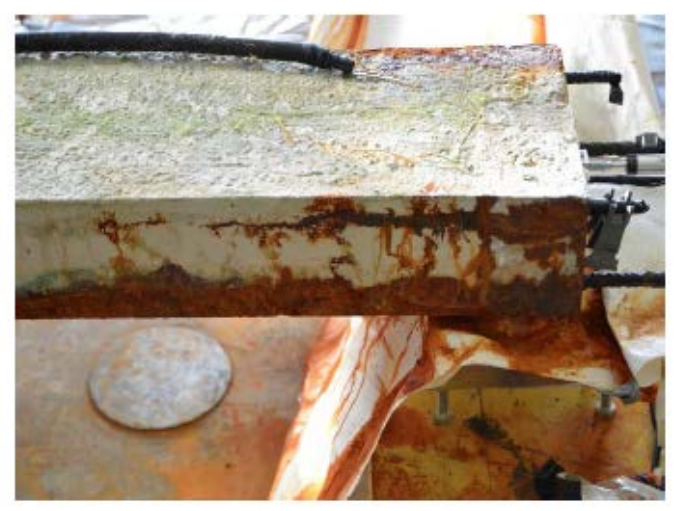

Fig. 4. Longitudinal cracks observed during corrosion

After the beams had reached the defined exposure time, the corroded steel was extracted to determine the actual steel loss. Each corroded beam was demolished. Top and bottom reinforcement bars were cut into $50 \mathrm{~cm}$ long pieces, which were later carefully cleaned by means of a mechanical cleaning system. The average mass loss of each reinforcement bar was estimated by the difference in its original mass, estimated from a 1-meter-long uncorroded sample made from the same steel type. The final corrosion values for each beam, including top and bottom reinforcement, are described in Table 1. The corrosion level presented is averaged over the whole reinforcement length.

Preliminary tensile tests were performed to the extracted bars to assess the variation of the mechanical properties. Fig. 5 depicted some tested specimens. As it was expected the corrosion produced by accelerated corrosion tests was mixed type uniform corrosion as well as pitting corrosion. Fig. 6 showed the final state of a corroded bar with $9 \%$ of corrosion level. As it is possible to all the bar length presented a clear cross-section but it is also possible to see different pits distributed along the same length. 


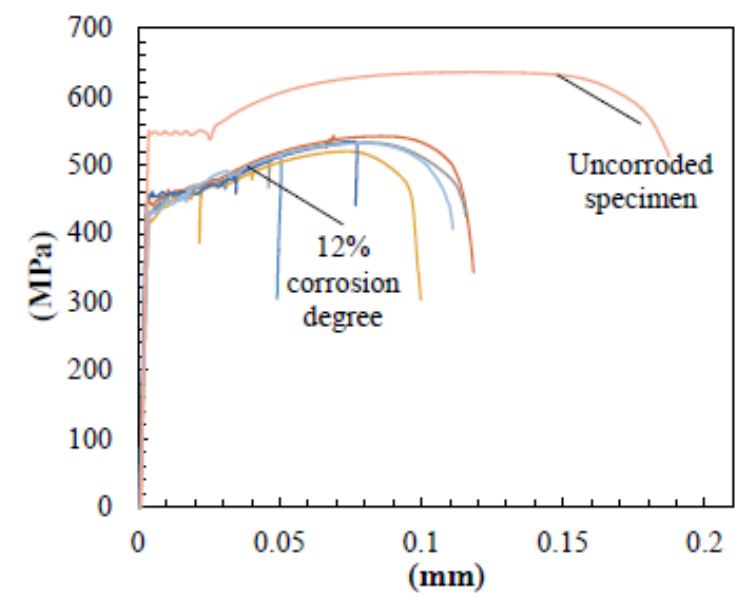

Figure 5. Stress-strain curves corroded (12\% avg corrosion degree) and uncorroded steel.

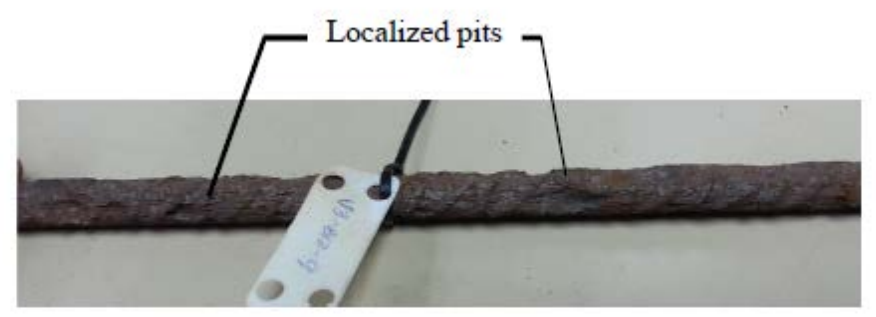

Fig. 6. Corroded steel bar mixed type pitting and uniform corrosion

\subsection{Deflections}

Fig. 7 depicts the measured deflections for all the tested specimens. It is possible to observe the differences between the deflections of the three groups subjected to different corrosion rates and the behaviour of each one during the corrosion exposure time. 


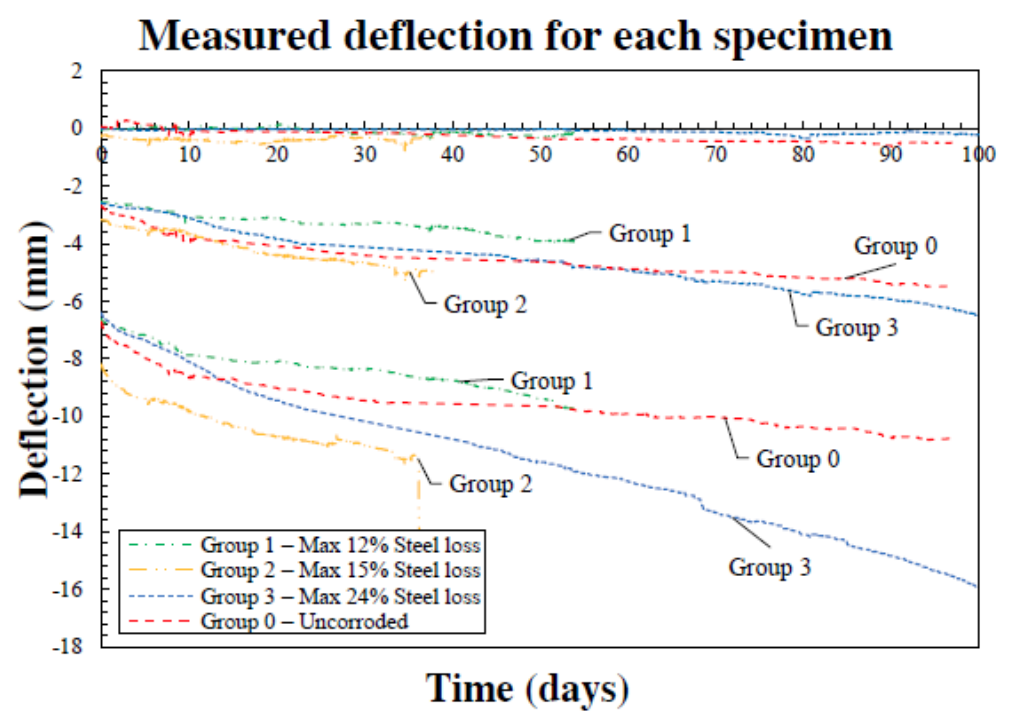

Figure 7. Registered deflections for all tested beams.

The following procedure has been used to study the effect of load level on the corrosion process. Firstly, for each load level, a normalized deflection value is obtained by dividing total deflection by instantaneous deflection. Then, the ratio between normalized deflection under load $2 \mathrm{P}$ and normalized deflection under load $\mathrm{P}$ is computed. This ratio is obtained for each corrosion group, and the results are plotted in Fig. 8. It can be seen that delayed deflections are more pronounced in the groups which underwent corrosion. Also, delayed deflection amplification due to corrosion is greater in the case of 2P-loaded specimens than in P-loaded specimens. In the long term, it seems that trend shapes for all groups tend to be similar. 


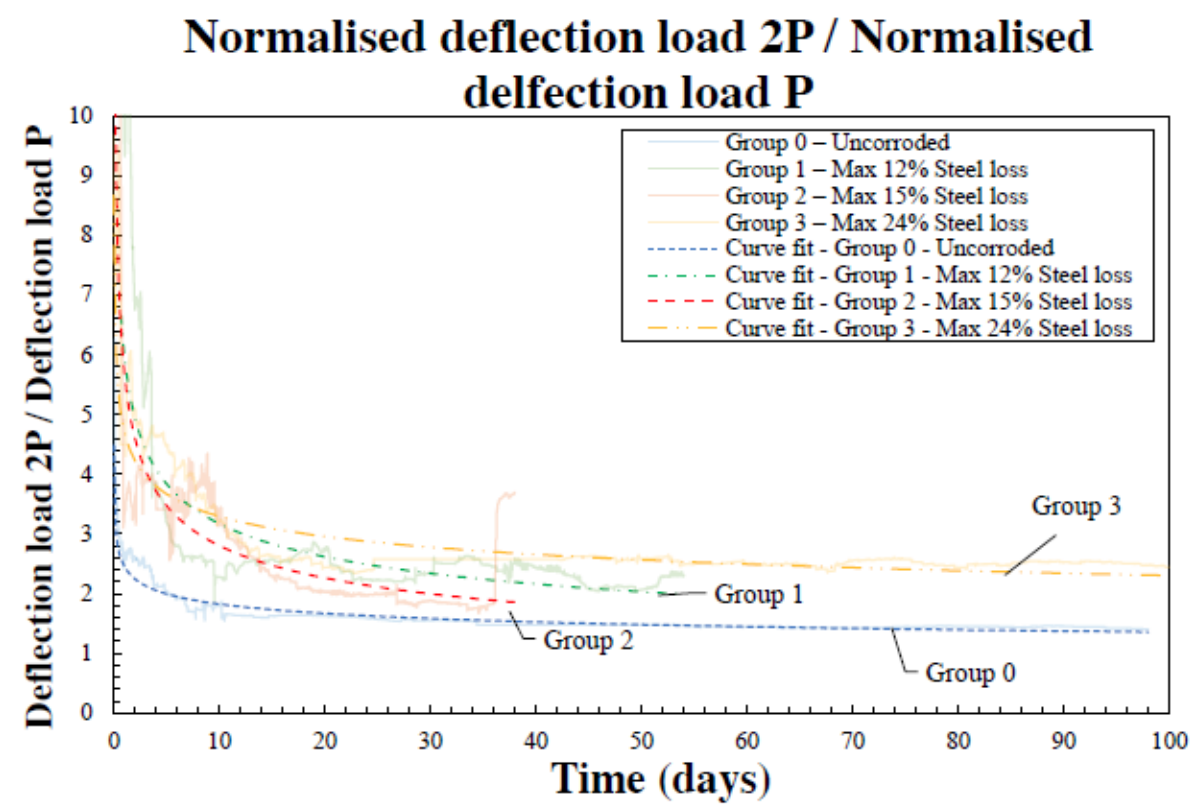

Figure 8. Deflection ratio: evolution of normalized deflection under $2 \mathrm{P}$ load divided by normalized deflection under $\mathbf{P}$ load,

with respect to time

Table 2. Comparison of the deflection ratio (deflection under $2 P$ load divided by normalized deflection under $P$ load) of corroded beam groups against uncorroded beam group at the end of their respective corrosion processes time

\begin{tabular}{lccc}
\hline $\begin{array}{l}\text { Last measurement } \\
\text { deflection }\end{array}$ & $\begin{array}{c}\text { Ratio P/2P corroded } \\
\text { specimen }\end{array}$ & $\begin{array}{c}\text { Ratio P/2P uncorroded } \\
\text { specimen }\end{array}$ & $\begin{array}{c}\text { Corroded/Uncorrod } \\
\text { ed specimens }\end{array}$ \\
\hline $\begin{array}{l}\text { Group } \\
\text { Uncorroded }\end{array}$ & - & -- & 1 \\
\cline { 2 - 4 } $\begin{array}{l}\text { Group } 1-\text { Max. } \\
\text { corrosion degree } 12 \%\end{array}$ & 0,43 & 0,47 & 0,92 \\
\cline { 2 - 4 } $\begin{array}{l}\text { Group } 2-\text { Max. } \\
\text { corrosion degree } 15 \%\end{array}$ & 0,4 & 0,48 & 0,82 \\
$\begin{array}{l}\text { Group 3- Max. } \\
\text { corrosion degree 24\% }\end{array}$ & 0,41 & 0,51 & 0,80 \\
\hline
\end{tabular}

Table 2 shows a summary of the aforementioned effect. The normalized deflection ratio for each group of beams, as measured at the end of their respective corrosion processes, is compared to the normalized deflection ratio for uncorroded beams. It can be seen that 
the ratio is significantly higher for all corroded groups, with an increase between $20 \%$ and $40 \%$ against the uncorroded beam, depending on the corrosion level attained.

\subsection{Reactions and bending moments redistributions}

All beams showed redistribution of reaction forces between the central support and both end supports. However, as expected, uncorroded specimens only presented short term redistribution because of the initial effect of creep and shrinkage; after that, each reaction remained almost constant over time. Fig. 9 depicts the average registered reaction at the beam-ends for all specimens. All graphs have been offset, subtracting from the readings the reaction value at $t=0$; in this way, only increment of reactions are shown, and the evolution of redistribution can be more easily interpreted.

\section{Measured reaction for each specimen}

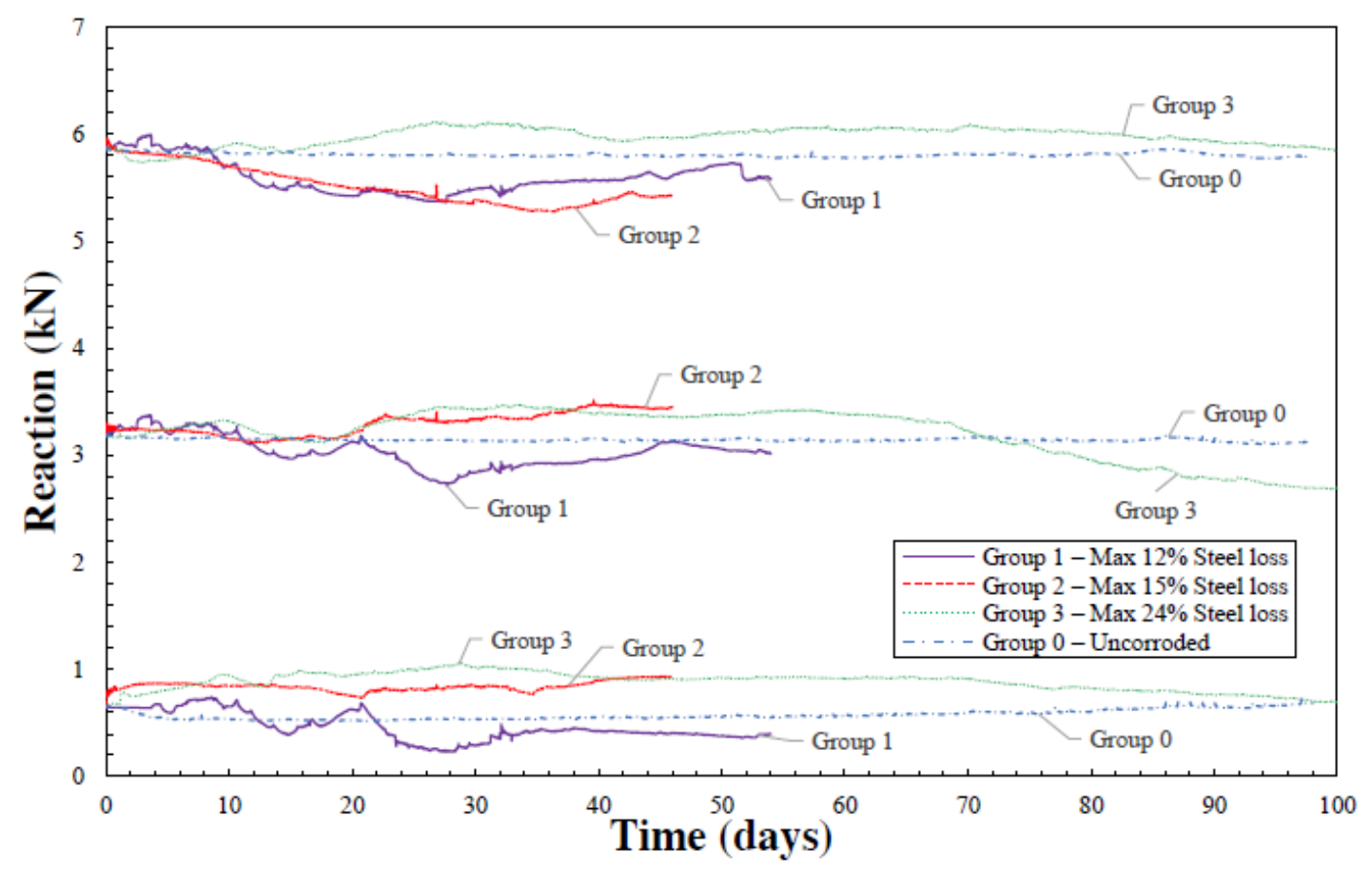

Figure 9. Overall reaction evolution for all the specimens

Using load balance calculations, it was possible to obtain the bending moment at the critical cross-sections (midspans and central support), which represented the maximum 
positive and the highest negative bending moment respectively. Fig. 10 describes the evolution of the bending moment at these sections. It seems that the relative effect of redistribution was actually lower at higher loads. In spite of this, all the beams presented some bending moment redistribution. It can be seen that the evolution of the bending moment did not follow a constant trend, but instead increased and decreased over time. Table 3 describes maximum and minimum redistribution values at the central crosssection (shown as a percentage of load redistribution with respect to initial load) for all specimens, comparing the maximum and minimum bending moment observed.

Table 3. Bending moment redistribution at central support cross-section (actual values and value as a percentage of bending moment at $\mathrm{t}=\mathbf{0}$ )

\begin{tabular}{lcccccc}
\hline & \multicolumn{2}{c}{ Self-weight } & \multicolumn{2}{c}{ Load P } & \multicolumn{2}{c}{ Load 2P } \\
\hline & $\begin{array}{c}\text { Max. } \\
(\mathrm{kN} \cdot \mathrm{m})\end{array}$ & $\begin{array}{c}\text { Min. } \\
(\mathrm{kN} \cdot \mathrm{m})\end{array}$ & $\begin{array}{c}\text { Max. } \\
(\mathrm{kN} \cdot \mathrm{m})\end{array}$ & $\begin{array}{c}\text { Min. } \\
(\mathrm{kN} \cdot \mathrm{m})\end{array}$ & $\begin{array}{c}\text { Max. } \\
(\mathrm{kN} \cdot \mathrm{m})\end{array}$ & $\begin{array}{c}\text { Min. } \\
(\mathrm{kN} \cdot \mathrm{m})\end{array}$ \\
Uncorroded & -1.03 & -0.68 & -4.54 & -4.39 & -8.03 & -7.77 \\
& $49.3 \%$ & $1.5 \%$ & $2.5 \%$ & $0.9 \%$ & $3.4 \%$ & $0.0 \%$ \\
Group 1 & -1.57 & -0.33 & -4.38 & -3.24 & -9.59 & -8 \\
& $190.8 \%$ & $39.0 \%$ & $30.2 \%$ & $12.67 \%$ & $15.60 \%$ & $3.3 \%$ \\
Group 2 & -0.3 & -0.29 & -4.79 & -3.8 & -10.81 & -9.13 \\
& $69.1 \%$ & $70.1 \%$ & $4.1 \%$ & $17.39 \%$ & $17.12 \%$ & $1.1 \%$ \\
Group 3 & -0.85 & 0.12 & -5.41 & -3.47 & -8.29 & -7.77 \\
& $0.0 \%$ & $114.1 \%$ & $27.0 \%$ & $18.5 \%$ & $5.9 \%$ & $5.2 \%$ \\
\hline
\end{tabular}

The maximum and minimum variations in Table 3 were attributed to corrosion of top and bottom steel reinforcement starting at different moments in time: before the beginning of top reinforcement corrosion, internal forces would redistribute so the bending moment at midspan would be reduced and the negative moment at the central support would increase. Once the top reinforcement started to corrode, this trend was reversed.

Since there is uncertainty regarding the initiation of the corrosion process in the top reinforcement, it is difficult to pinpoint which phenomena are accountable for internal 
forces redistribution at each moment in time. It is nevertheless plausible that the change in trend (first, redistribution from midspans to central support, switching later to redistribution from support to midspans) takes place when top reinforcement corrosion has progressed enough to significantly weaken the section over the central support.

\subsection{Steel stresses}

Some of the gauges recorded information about the steel strains despite the extremely aggressive environmental conditions. All the gauges stopped working before the end of the test. With the data that were actually registered, it was possible to observe the steel behaviour due to corrosion. Fig. 11 shows the stress in reinforcement steel at mid-span and central support. 
Beam G1_2P_2P

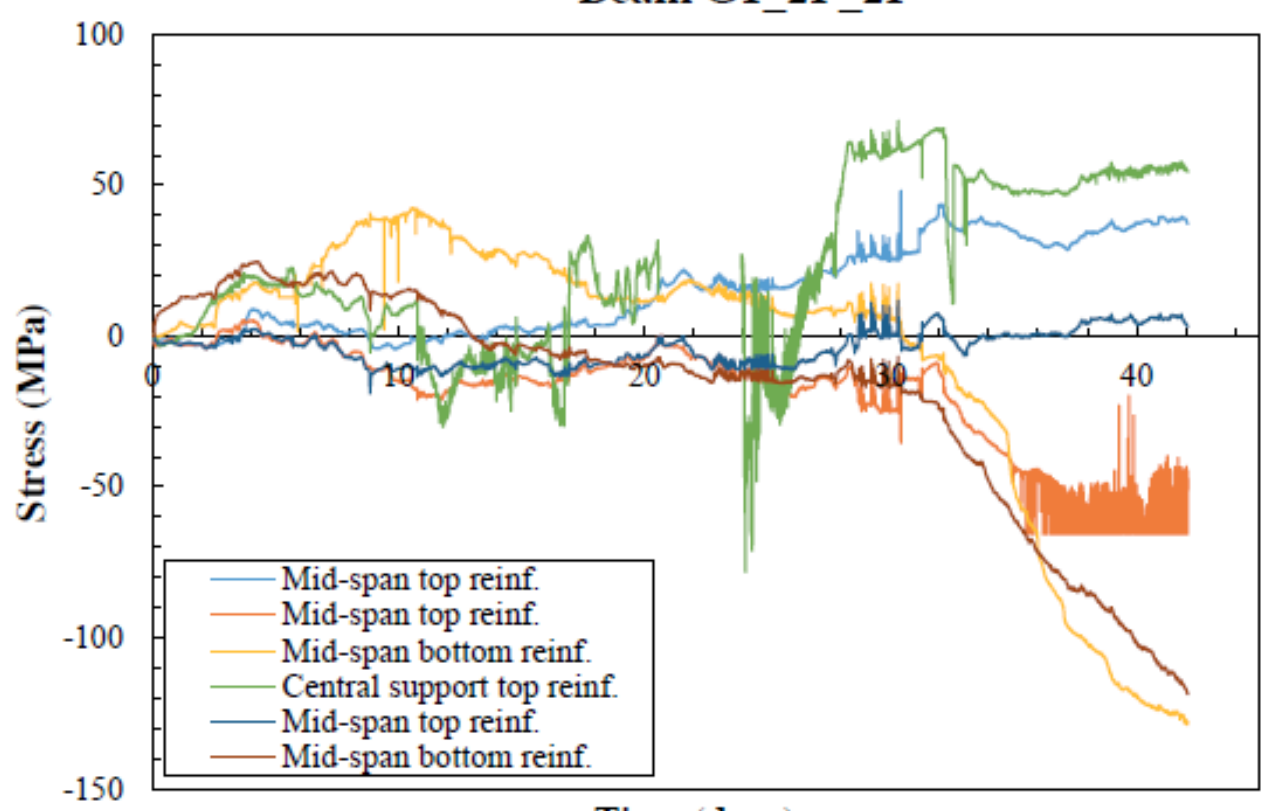

Time (days)

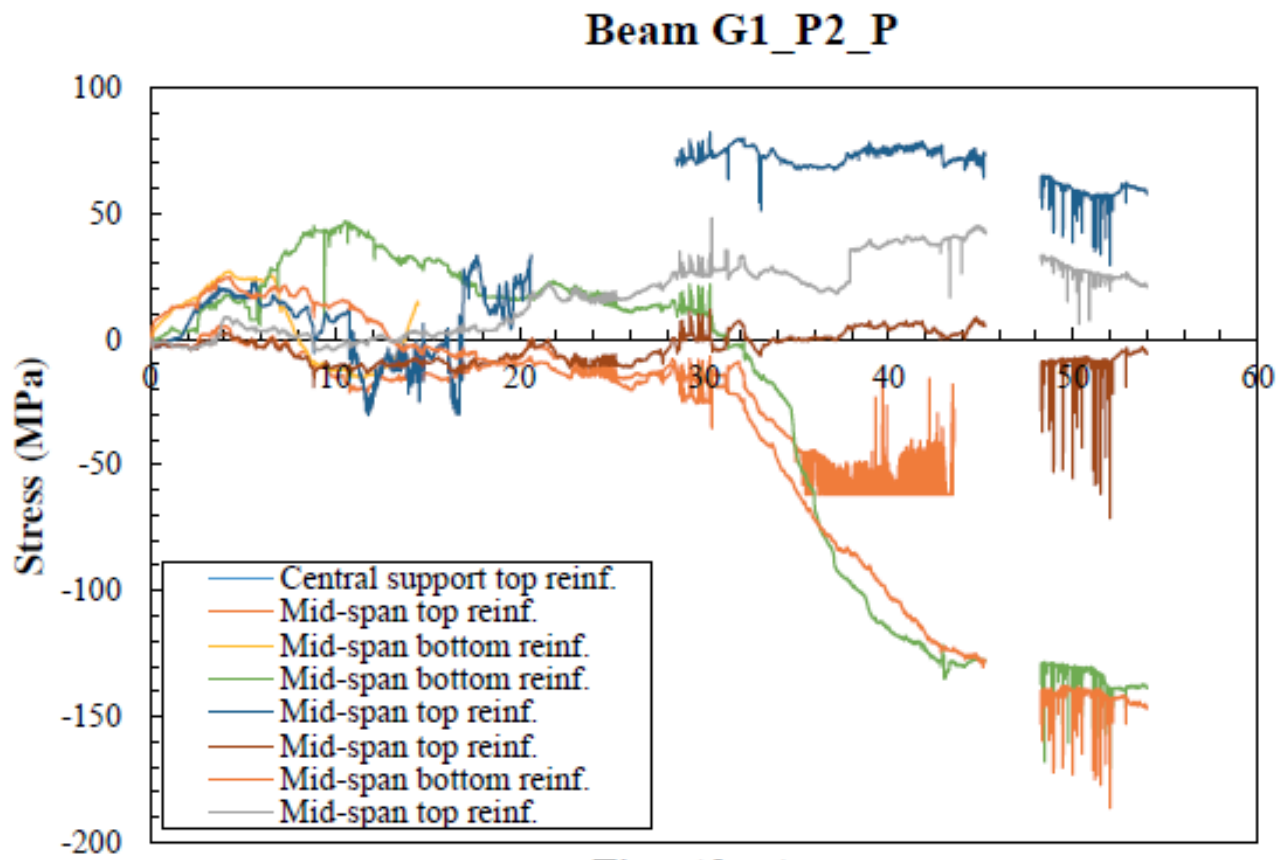

Time (days) 


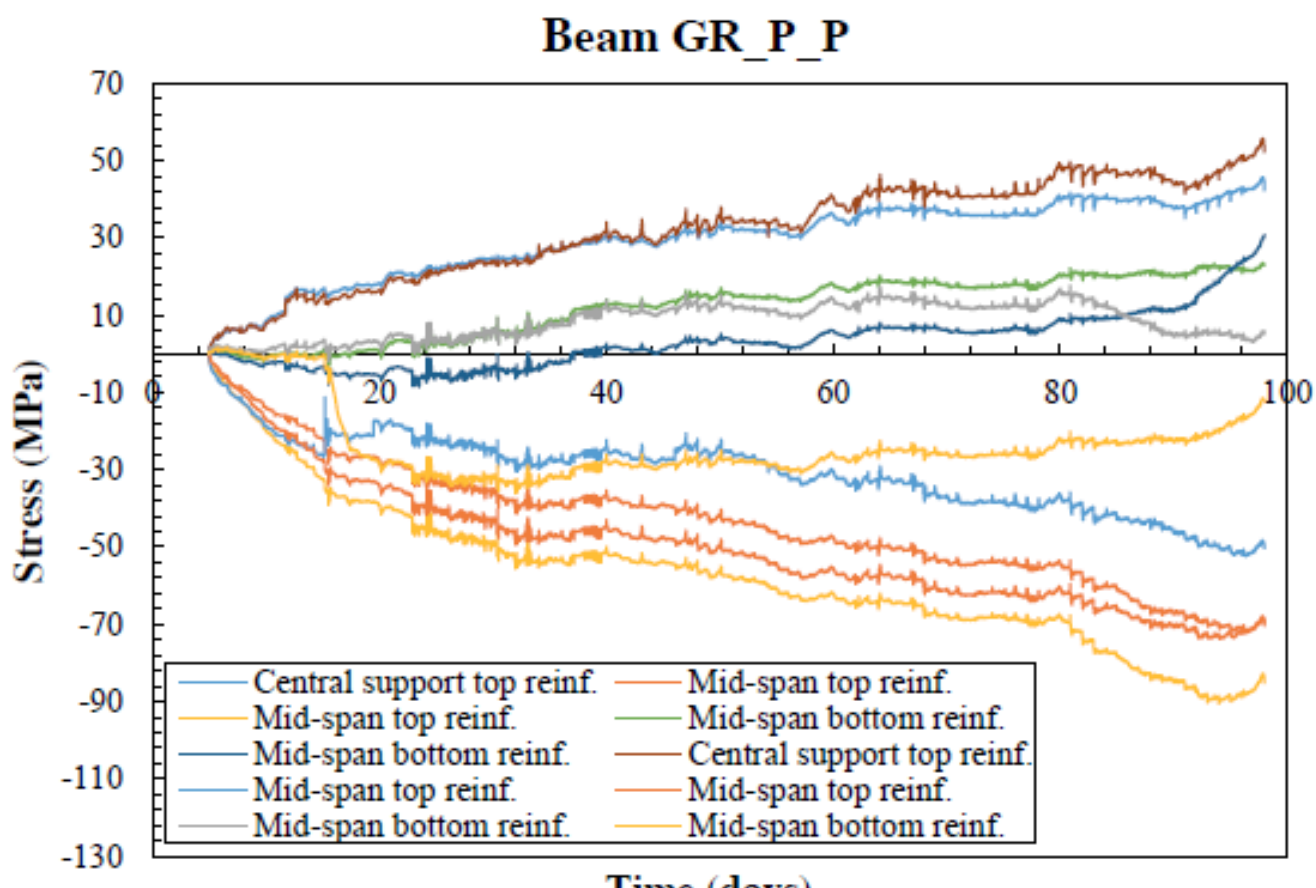

Time (days)

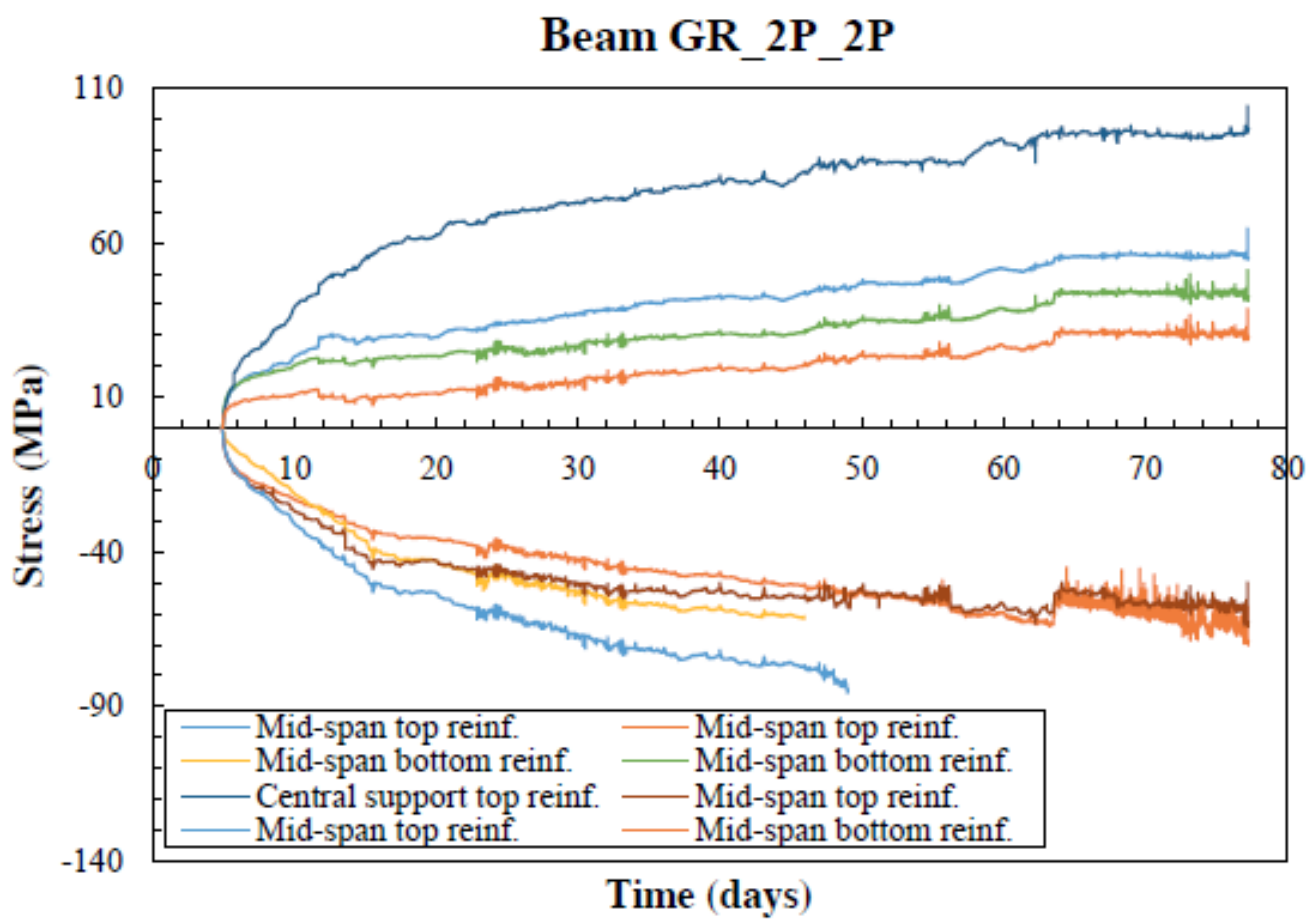

Figure 11. Steel stress evolution during corrosion procedure

Stress on steel reinforcement described several fluctuations too, not just following loss of steel cross-section but also because of the internal force redistribution. According to the evolution of stress, the maximum increase was usually lower than the one expected 
due to the loss of cross-section itself, as one would have in the case of an isostatic beam, for example. This means that the redistribution of internal forces, typical of statically indeterminate structures, reduced the stress level on corroded steel bars reducing the possibility of premature failure, that behaviour was also reported by Cairns et al. [20].

In Fig. 11 - GR_2P, uncorroded beam, it can be seen that the stress increment on the top reinforcement over the central support is at least about $100 \mathrm{MPa}$ after 80 days, due to creep. On the other hand, Fig. 11 - G1_2P shows roughly the same stress increment for the same reinforcing layer but after 20 days, describing a descending trend from there to last measurement at 80 days. Thus, the maximum stress level was observed for both specimens at the same cross-section, but at different times. The same behaviour was registered for the tensile reinforcement at the mid-span cross-section. The same response can be inferred when comparing Fig. 11 - GR_P, uncorroded beam, with Fig. 11 - G1_P: the tensile stresses hardly exceeded the maximum stress increment with respect to the uncorroded specimen.

Regarding mid-span top reinforcement, Fig. 10 shows that, in general, they were relieved of stress, presenting positive stress increments.
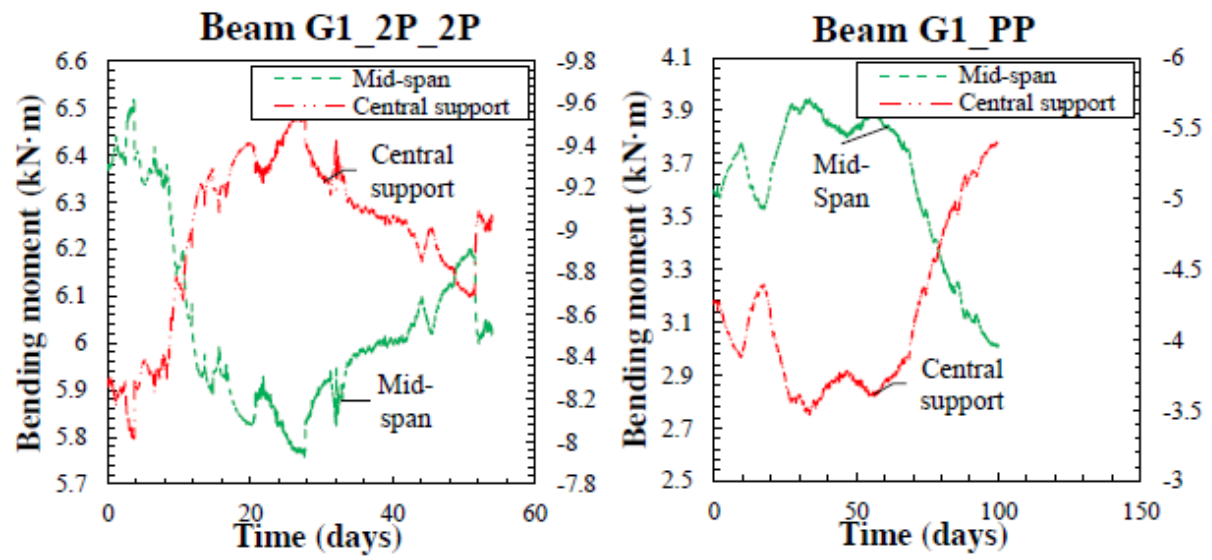

Figure 10. Bending moment evolution at mid-span and central support cross-sections. a) Beam G1_2P b) Beam G1_P3_P 


\subsection{Relative slips between end bars and concrete}

No significant slips between the ends of the reinforcing bars and the concrete were observed in any specimens during the corrosion procedure. No influence of the corrosion level on the relation between load and slip at the bar end of the bottom reinforcement steel was observed either.

\section{Numerical model used to predict the effects of deterioration.}

\subsection{Brief description of the numerical model}

A previously developed nonlinear and time-dependent analysis model [11] was modified to include the effects of steel and concrete deterioration due to the corrosion phenomenon. The internal organization of the model, designed to perform step-by-step analyses of segmentally erected structures as well as to deal with any subsequent changes along the entire structure service life, makes possible to implement the effects of deterioration in a straightforward manner.

A filament beam element with arbitrary cross-section and 13 degrees of freedom is used by the model together with nonlinear constitutive equations for the steel and concrete filaments to account for the nonlinear response under increasing loading levels. These capabilities, together with a the time-dependent scheme taking into account load and temperature histories, creep, shrinkage, aging and steel relaxation, enable the model to assess existing deteriorated structures at any time of its structural service life (as well as, of course, newly built structures).

\subsection{Loss of steel area and cover cracking}

The non-linear model CONS [17] was modified to reproduce the uniform reinforcement steel cross-section reduction due to corrosion in the bars. Pitting or localized corrosion has not been included in the model for the time being. On the other hand, the model 
does not simulate external aggressive agent penetration. In order to account for the effects of the reinforcement deterioration, the following parameters defining the damage evolution (in terms of geometry of the reinforcing bars) are provided to the structural analysis model:

- Initiation time $\left(\mathrm{T}_{\mathrm{i}}\right)$ : The starting time of the deterioration phenomena in terms of reinforcement cross-section reduction (time-to-corrosion). In an accelerated corrosion test, this should be the connection day.

- Final time $\left(\mathrm{T}_{\mathrm{f}}\right)$ : Is the initial time plus the time elapsed, in which the analysis is performed.

- Percentage of corroded cross-section of the reinforcement in the considered element: this parameter, together with initial time and final time, determines corrosion rate. It is possible to express this value in terms of velocity in $\mathrm{mm} / \mathrm{day}$ (corrosion penetration) or in terms of the percentage of total cross-section reduction during the defined exposure time. In the last case, the model will compute the value of corrosion rate from the introduced values.

- Rebar diameter: in the original model, only the amount of steel per filament is needed. In this case, since the development of corrosion phenomena depends on rebar diameter, this parameter has to be provided.

The evolution of cross-section over time is expressed as a function of the described parameters according to Equation 3.

$$
A_{s}(t)=n_{b a r} \cdot \frac{\pi}{4} \cdot\left(\varnothing_{0}-v \cdot \Delta t\right)^{2}=\frac{4 \cdot A_{s o}}{\pi \cdot \emptyset_{o}^{2}} \cdot \frac{\pi}{4} \cdot\left(\varnothing_{0}-v \cdot \Delta t\right)^{2}=A_{s o}\left(1-\frac{v \cdot \Delta t}{\emptyset_{0}}\right)^{2} \text { (eq.) } 3
$$

Where:

$v$, is obtained from the equation $v=\frac{\emptyset_{0} \cdot\left(1-\sqrt{\%_{\text {acorr }}}\right)}{\text { Tfin-Tini }}$, in $\mathrm{mm} /$ day 
$\Delta t$, is the increment of time from $\mathrm{T}_{\mathrm{i}}$

$\emptyset_{0}$, is the nominal diameter of the steel bars

$A_{s o}$, is the amount of initial Steel in the section, corresponding to the initial filament area.

Following Equation 3, the model incorporates the steel area value in each time step and proceeds to compute the structural state. The loss of steel area results in a reduction in capacity and in stiffness of any cross section affected by corrosion. Thus, when performing the computation of internal forces, by integration of the stresses at the sections placed at the element's Gauss points, the external forces will not be balanced by the internal ones. Then, these unbalanced forces are automatically introduced in the non-linear iterative scheme, until equilibrium is obtained. As a consequence of corrosion, increments of stresses and strains in concrete and steel, increments of deflections (due to the loss of stiffness) and redistribution of internal forces takes place to satisfy equilibrium and compatibility conditions for the current state of the materials.

\subsection{Comparison between the predicted and the experimental results}

A comparison between the theoretical and the experimentally obtained results was performed in order to assess the capacity of the structural analysis model to predict the structural effects of deterioration. Fig. 12 represents the delayed deflection for uncorroded beams and for G2_P, G3_9 and G1_SW. 

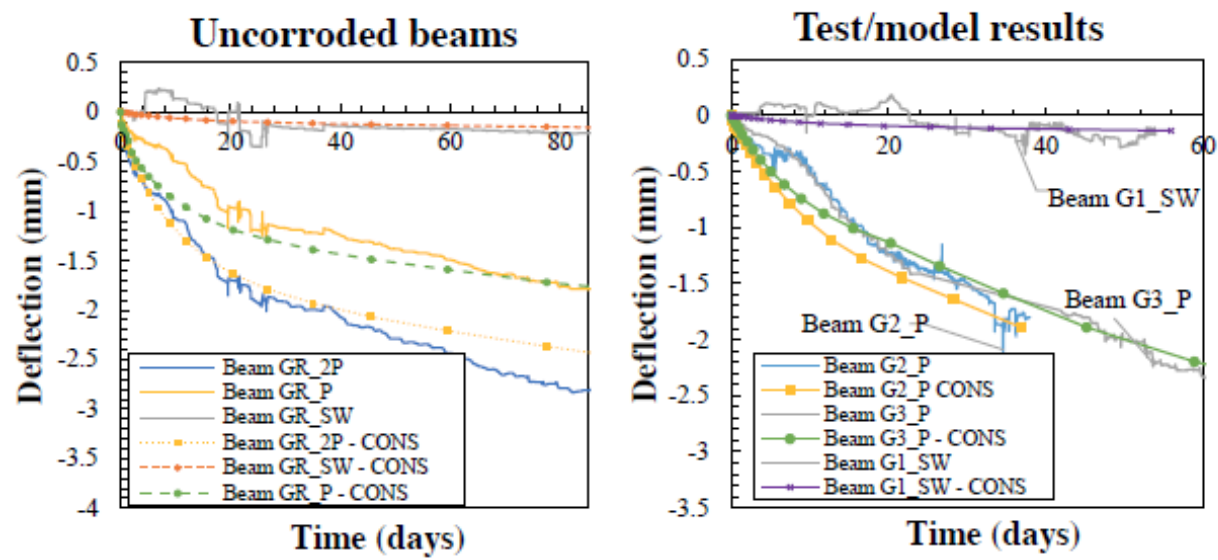

Figure 12. a) Uncorroded specimens b) Beam G1_SW, Beam G2_P, Beam G3_P

The model adjusts the deflections quite accurately over time in the case of uncorroded beams. On the other hand, corroded specimens present more dispersion. There are significant differences between predicted load redistribution values and experimental registered data. However, it should be taken into account that the structural scheme and the type of loading of the studied structures do not favour force redistribution even in the case of non-corroded structures.

\section{Discussion}

Four factors were identified as the main reasons for the corrosion of top reinforcement. Firstly, due to the depth value chosen for the cross-section, the distance between upper and lower reinforcement is small (less than $10 \mathrm{~cm}$ ). Secondly, since the cathode was placed in the middle of the cross-section, the distance from top and bottom reinforcement to the cathode was the same. Thirdly, the beam was saturated because of the irrigation system. Finally, both the top and the bottom reinforcement were depassivated because of the $\mathrm{NaCl}$ solution added during concrete mixing. These factors translated into a change of the initial corrosion scheme, switching to one where the top reinforcement took part and started to corrode when humidity conditions were optimal. 
It is extremely difficult to estimate initiation time of top reinforcement corrosion in each beam because many factors (such as beam humidity, pore mesh or cracking) have large uncertainties. A potential initiation time of the top reinforcement has been nevertheless estimated through the analysis of reaction redistribution measurements. However, it is hard to confirm this parameter, even after the corroded rebar was extracted and cleaned to measure actual corrosion level, since not all specimens showed top reinforcement corrosion, and in some cases, only the external continous top reinforcement was corroded (being the layer more exposed to irrigation water).

As described above, deflections are strongly influenced by corrosion of steel. In general terms, a significant increment of deflection was observed, severely reducing the structure performance at service load levels. The main reason being the loss of stiffness because of steel cross-section reduction. In addition, other authors have stated the increment of the longitudinal strains as a reason for higher deflections [7, 22]. The reduction of steel cross-section could be another reason for increasing deflections, contributing to the overall stiffness reduction.

Another interesting phenomenon observed during the steel corrosion process was the effect of load. As previously noted, higher loads produced nonlinear amplification of deflections. In addition to the influence of creep, other phenomena induced an increment of deflections with the increase of corrosion level. It could be attributed to an amplification effect of the loss of cross-section stiffness with the applied load.

A significant impact of steel corrosion on load redistribution was observed. The effect of the reduction of steel in the cross-section and the modification of its mechanical properties is also observed on load redistribution. Each group of beams submitted to the same theoretical corrosion level followed quite a similar behaviour on load 
redistribution, which indicated that the corrosion on top and bottom steel started roughly at the same time in each and every beam. Since strain gauges did not survive the full corrosion procedure, steel stress remains partly unknown; this renders difficult the interpretation of the load distribution. In spite of this, the capacity of statically indeterminate beams to redistribute loads made possible to observe some effects as stated.

The increase in stress due to cross-section reduction and redistribution detected in corroded elements is almost always smaller than the increase observed in uncorroded beams with the same reinforcement and the same load level. This means that the structure remains relatively safe until very high corrosion levels are reached. For instance, beam G3_2P, which attained a high corrosion degree, collapsed at the end of exposure time under the effect of the permanent load applied. Failure took place at the intermediate support, where negative moments are strongest and maximum local corrosion was observed a posteriori (local steel loss up to $40 \%$ ). It can be seen, through the study of the evolution of bending moment in the intermediate support section, that there is indeed moment redistribution towards the end supports, which kept the beam in a safety zone for an extended period of time. The same phenomenon took place in other tested elements in the opposite sense: concentrated corrosion in the bottom reinforcement produced redistribution towards the intermediate support.

Modelling the evolution of deterioration due to reinforcing steel corrosion is a difficult task. Many variables are affected by corrosion besides steel cross-section reduction. The preliminary tensile test for corroded steel showed a variation of the mechanical steel properties compared to uncorroded steel, see Fig. 5. Decreases of the modulus of elasticity, yield strength, tensile strength and maximum and ultimate strains were observed. Furthermore, the relationship between this decrease and corrosion level is 
nonlinear, which indicates a degradation of steel at high corrosion levels; this behaviour has already been observed by other researchers [1].

The influence of other corrosion-dependent mechanic factors, such as stress concentration in pitting crack tips or local bending due to neutral axis shifts, produces nonuninform stress distributions throughout the section [1]. Also, material nonuniformity due to modern manufacturing procedures such as TEMPCORE tends to exacerbate these phenomena [1]. A more detailed description of material properties is necessary to better adjust the model response. In addition, a more complex representation of splitting phenomena would be needed to discern which parts of the concrete section contribute to total resistance at each moment in time. Other authors have observed variations in mechanical properties of the concrete surrounding corroded bars [23, 24]. This should also be included in the model to take into account the full effect of corrosion if the goal is to accurately reproduce deterioration processes in statically indeterminate structures. In particular, the effect of corrosion on the loss of ductility of the corroded bars is an important phenomenon which can limit the redistribution capacity and, therefore, the ultimate capacity of statically indeterminate corroded structures, which is currently implemented in the described non-linear analysis model.

\section{Conclusions}

An experimental campaign on two-span continuous RC beams under forced corrosion, subjected to different corrosion rates and different sustained loads, has been performed. Predictions of the tests results were made using a nonlinear and time dependent analysis model, modified to account for the corrosion effects. Based on the results of the study, the following conclusions can be drawn: 
(1) For the same load level, higher deflections were observed for corroded than for uncorroded specimens. Furthermore, for the same corrosion levels, the deflections measured were more than proportional to the load level, as shown by the comparison between normalized deflections under $2 \mathrm{P}$ and P loads. In other words, the amplification of deflections in corroded specimens increases nonlinearly with the load level.

(2) Internal forces redistribution between the different parts of the structure was observed; it appeared to be more pronounced at lower load levels. Up to $20 \%$ force redistribution in the main cross-section under $2 \mathrm{P}$ load and $40 \%$ for $\mathrm{P}$ load took place due to steel corrosion only.

(3) The stress levels measured by means of the strain gauges described significant variations not only due to the loss of cross-section itself but also due to the above-mentioned internal forces redistributions. However, the maximum increase in stress level observed was roughly the same on corroded and uncorroded specimens.

(4) It has been observed that reinforcement corrosion enhances internal forces redistribution from corroded sections to uncorroded ones, relieving stress in the areas that are damaged the most. Thus, the capacity to redistribute internal forces inherent to statically indeterminate beams seems to provide additional safety in regard to corrosion and deterioration phenomena.

(5) The mechanical properties of corroded steel bars, which are some of the most relevant aspects to take into account in the assessment of steel corroded structures, are considerably modified by corrosion. Furthermore, the degradation of material properties does not follow the corrosion degree linearly, becoming more intense with the increase in corrosion level. 
(6) Modelling deterioration phenomena is a difficult task due to the uncertainty of the many factors to be included in the model to take into account all the deterioration variables involved. The presented model can predict quite accurately the structure deflection; however, it did not properly reproduce internal forces redistribution.

\section{Acknowledgments}

The authors wish to acknowledge the financial support of The Ministry of Economy and Competitiveness of the Government of Spain (MINECO) for providing funds for project BIA2009-11764 and the European Regional Development Funds (ERDF). The financial support of Infrastructures de Catalunya (ICAT) is also highly appreciated. 


\section{References}

1. Fernandez I, Bairán JM, Marí AR (2015) Corrosion effects on the mechanical properties of reinforcing steel bars. Fatigue and $\sigma-\varepsilon$ behavior. Constr Build Mater 101:772-783. doi: 10.1016/j.conbuildmat.2015.10.139

2. Al-Sulaimani G, Kaleemullah M, Basunbul I (1990) Influence of corrosion and cracking on bond behavior and strength of reinforced concrete members. ACI Struct. J.

3. Alonso C, Andrade C, Rodriguez J, et al. (1998) Factors controlling cracking of concrete affected by reinforcement corrosion. Mater Struct 31:435-441.

4. Tutti K (1997) Corrosion of steel in concrete. 6-15. doi: 10.4324/9780203414606_chapter_2

5. Broomfield J (2002) Corrosion of steel in concrete: understanding, investigation and repair, 2nd Ed. Taylor \& Francis, Abingdon, United Kingdom

6. Muñoz Noval A (2009) Comportamiento de vigas hiperestáticas de hormigón armado corroídas y reparadas con mortero: pérdida de propiedades mecánicas del acero de refuerzo y fisuración del recubrimiento de hormigón por corrosión.

7. Malumbela G, Alexander M, Moyo P (2009) Steel corrosion on RC structures under sustained service loads - A critical review. Eng Struct 31:2518-2525. doi: 10.1016/j.engstruct.2009.07.016

8. Malumbela G, Moyo P, Alexander M (2009) Behaviour of RC beams corroded under sustained service loads. Constr Build Mater 23:3346-3351. doi: 10.1016/j.conbuildmat.2009.06.005

9. Biondini F, Vergani M (2014) Deteriorating beam finite element for nonlinear analysis of concrete structures under corrosion. Struct Infrastruct Eng 11:519532. doi: 10.1080/15732479.2014.951863

10. Ferreira D, Bairán J, Marí A, Faria R (2013) Nonlinear analysis of RC beams using a hybrid shear-flexural fibre beam model. Eng Comput 31:1444-1483. doi: 10.1108/EC-04-2013-0114

11. Marí AR, Asce M, Oller E, Bairán JM (2011) Predicting the Response of FRPStrengthened Reinforced-Concrete Flexural Members with Nonlinear Evolutive Analysis Models. 15:799-809. doi: 10.1061/(ASCE)CC.1943-5614.0000214.

12. Monti BG, Filippou FC, Member A, Spacone E (1997) Finite element for anchored bars under cyclic load reversals. 614-623.

13. Mohr S, Bairán JM, Marí AR (2010) A frame element model for the analysis of reinforced concrete structures under shear and bending. Eng Struct 32:39363954. doi: 10.1016/j.engstruct.2010.09.005

14. Maaddawy TEA El, Soudki KKA (2003) Effectiveness of impressed current technique to simulate corrosion of steel reinforcement in concrete. J Mater Civ ... 41-47.

15. Caré S, Nguyen QT, L’Hostis V, Berthaud Y (2008) Mechanical properties of the rust layer induced by impressed current method in reinforced mortar. Cem Concr Res 38:1079-1091. doi: 10.1016/j.cemconres.2008.03.016

16. Lu C, Jin W, Liu R (2011) Reinforcement corrosion-induced cover cracking and its time prediction for reinforced concrete structures. Corros Sci 53:1337-1347. doi: 10.1016/j.corsci.2010.12.026

17. Marí AR (2000) Numerical simulation of the segmental construction of three dimensional concrete frames. Eng Struct 22:585-596. doi: 10.1016/S01410296(99)00009-7 
18. Badawi M, Soudki K (2005) Control of Corrosion-Induced Damage in Reinforced Concrete Beams Using Carbon Fiber-Reinforced Polymer Laminates. J Compos Constr 9:195-201. doi: 10.1061/(ASCE)1090-0268(2005)9:2(195)

19. Saifullah M, Clark LLA, Sailfullah M, Clark LLA (1994) Effect of Corrosion Rate on the Bond Strength of Corroded Reinforcement. In: Press SA (ed) Proc. Int. Conf. Corros. Corros. Prot. steel Concr. University of Sheffield, pp 591-600

20. Cairns J, Coakley E (2015) Deformation of continuous reinforced concrete beams during patch repair. Struct. Concr.

21. ASTM Standard G1 (2011) Standard practice for preparing, cleaning, and evaluating corrosion test specimens.

22. Malumbela G, Alexander M, Moyo P (2010) Interaction between corrosion crack width and steel loss in RC beams corroded under load. Cem Concr Res 40:14191428. doi: 10.1016/j.cemconres.2010.03.010

23. Quagliaroli M (2014) From Bidimensional towards Monodimensional Modeling of Sound and Damaged Reinforced Concrete Structures.

24. Biondini F, Bontempi F, Frangopol DM, Malerba PG Cellular Automata Approach to Durability Analysis of Concrete Structures in Aggressive Environments. J Struct Eng 130:1724-1737. 